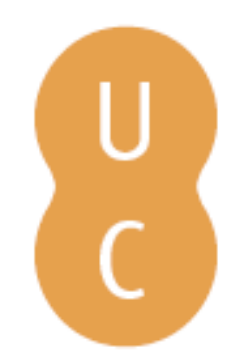

\title{
nommalina
}

\section{Propaganda Artística no Estado Novo: arte portuguesa na Campanha Nacional de Educação de Adultos}

\author{
Autor(es): Rosmaninho, Nuno \\ Publicado por: Imprensa da Universidade de Coimbra \\ URL \\ persistente: URI:http://hdl.handle.net/10316.2/39008 \\ DOI: $\quad$ DOI:http://dx.doi.org/10.14195/978-989-26-1064-1_14 \\ Accessed : $\quad$ 26-Apr-2023 13:09:16
}

A navegação consulta e descarregamento dos títulos inseridos nas Bibliotecas Digitais UC Digitalis, UC Pombalina e UC Impactum, pressupõem a aceitação plena e sem reservas dos Termos e Condições de Uso destas Bibliotecas Digitais, disponíveis em https://digitalis.uc.pt/pt-pt/termos.

Conforme exposto nos referidos Termos e Condições de Uso, o descarregamento de títulos de acesso restrito requer uma licença válida de autorização devendo o utilizador aceder ao(s) documento(s) a partir de um endereço de IP da instituição detentora da supramencionada licença.

Ao utilizador é apenas permitido o descarregamento para uso pessoal, pelo que o emprego do(s) título(s) descarregado(s) para outro fim, designadamente comercial, carece de autorização do respetivo autor ou editor da obra.

Na medida em que todas as obras da UC Digitalis se encontram protegidas pelo Código do Direito de Autor e Direitos Conexos e demais legislação aplicável, toda a cópia, parcial ou total, deste documento, nos casos em que é legalmente admitida, deverá conter ou fazer-se acompanhar por este aviso.

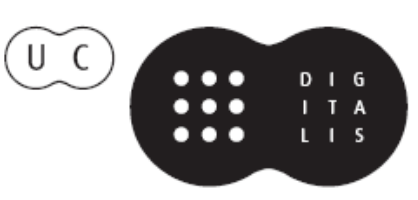


A L B ERTO PENA-RODR ÍGUEZ HELOISA PAULO

COOR D.

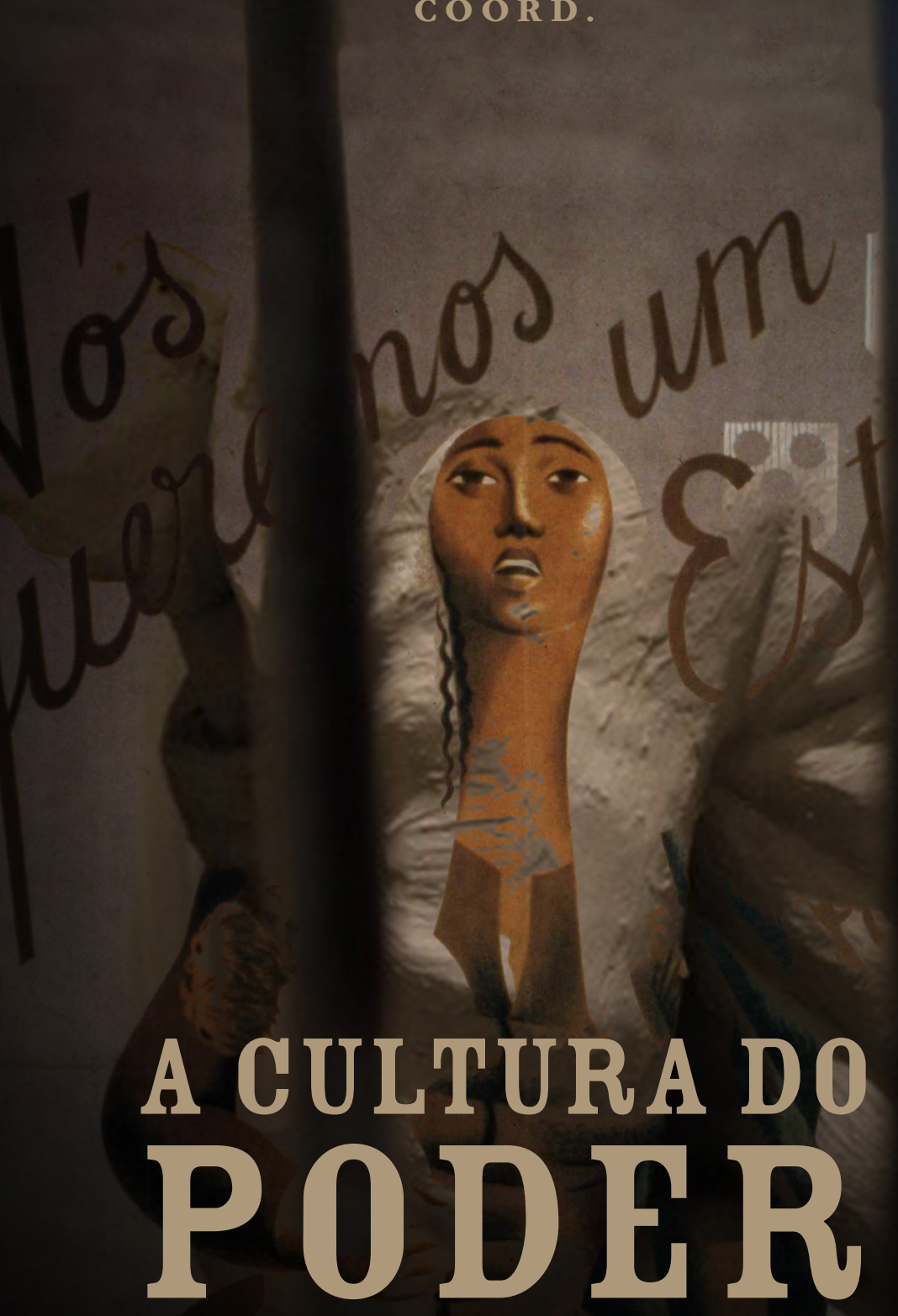

A PROPAGANDA INOS ESTADOS AUTORITÁRIOS 


\section{PROPAGANDA ARTÍSTICA NO ESTADO NOVO: ARTE PORTUGUESA NA CAMPANHA NACIONAL DE EDUCAÇÃO DE ADULTOS}

Nuno Rosmaninbo

Quando Oliveira Salazar subiu ao poder, os dilemas identitários da arte já ocupavam os intelectuais e artistas há cem anos. No entanto, as novas circunstâncias políticas e o próprio desenvolvimento dos discursos nacionais conferiram características particulares ao Estado Novo.

A deriva nacional da arte conheceu seis fases. A primeira, entre os anos dez e quarenta do século XIX, é marcada pela incerteza sobre as possibilidades portuguesas de alcançar uma especificidade colectiva. Na segunda, entre 1841 e 1890, assiste-se ao arranque esperançoso de um novo padrão cultural assente nas manifestações populares e eruditas e ao reconhecimento de tópicos de enorme importância futura, como o estilo manuelino, a escola portuguesa de pintura e a pintura de costumes. A terceira, de 1891 a 1920, encontra o tema da casa portuguesa, faz triunfar a ruralidade como valor de referência, recobre todos os assuntos com um poderoso e reconstituinte manto caracterológico e exalta-se com a descoberta dos painéis de Nuno Gonçalves. Na quarta, entre 1921 e 1940, vive-se uma época de extremos: o nacionalismo artístico exaspera-se no combate à ameaça internacionalista trazida pelas vanguardas. 
É uma luta que parece resolver-se a contento da identidade nacional, embora as fórmulas do equilíbrio apontem para uma supremacia do indivíduo que em breve produzirá efeitos drásticos. A quinta fase, entre 1941 e 1970, com certezas extremas acerca da intemporalidade do espírito português, alimenta a vigorosa historiografia de Reynaldo dos Santos mas vai deixando cada vez mais indiferentes os jovens artistas. E são estes que na sexta fase, depois do Estado Novo, manifestarão um alheamento por vezes ostensivo perante uma questão conotada com o salazarismo. ${ }^{1}$

O Roteiro da Arte Portuguesa, publicado no âmbito da Campanha Nacional de Educação de Adultos em meados dos anos cinquenta, reflecte um pensamento sereno e dogmático sobre o assunto. Começa por ser um manual escolar, caracterizando as Idades da Pedra, do Bronze e do Ferro e integrando o caso português em cada uma delas. Nem nestes remotos tempos nem nas artes das épocas romana, visigótica e moçárabe se encontra qualquer veleidade identitária portuguesa. Esse enfoque surge a seguir. O Roteiro sugere que a influência francesa durante a Reconquista tornou "possível o aparecimento dum estilo românico peninsular, que se inspira no românico borgonhês». ${ }^{2}$ Daqui para diante, cada estilo é exposto a partir de quatro ou cinco aspectos: influências estrangeiras, atributos que exprimem a especificidade portuguesa, principais características

1 Esta cronologia e o enquadramento geral do problema estão desenvolvidos no ensaio A Deriva Nacional da Arte e numa antologia dos séculos XIX a XXI, em preparação. Entre os estudos que dedicámos ao assunto, ver sobretudo "As múltiplas facetas da arte nacional", in PITA, António Pedro e TRINDADE, Luís (coord.), Transformações Estruturais do Campo Cultural Português (1900-1950). Coimbra: Ariadne Editora e CEIS20, 2005, pp. 373-400 (2. ${ }^{a}$ edição: Coimbra, CEIS20 - Centro de Estudos Interdisciplinares do Século XX, 2008, pp. 311-334) e "Historiografia artística no Estado Novo. A oposição discreta", in CORDEIRO, Carlos (coord.), Autoritarismos, Totalitarismos e Respostas Democráticas. Coimbra e Ponta Delgada: CEIS20 e Centro de Estudos Gaspar Frutuoso da Universidade dos Açores, 2011, pp. 167-175.

${ }^{2}$ Roteiro da Arte Portuguesa, s. 1., Campanha Nacional de Educação de Adultos, s. d., p. 75. Adoptamos este título, que se encontra na capa do volume. Na página de rosto, indica-se Roteiro de Arte Portuguesa. 
dos imóveis, edifícios fundamentais e, por fim, a escultura e a pintura. A particularidade portuguesa desenha-se nos dois primeiros tópicos, numa espécie de balanço entre o que vem de fora e o que é de dentro.

\section{Defesa dos monumentos}

O volume está concebido para amar a pátria através dos monumentos. Desde o Romantismo que esta concepção sustenta a principal linha de defesa do património, como se conclui da leitura dos artigos publicados por Alexandre Herculano na revista Panorama em 1838 e 1839. ${ }^{3}$ O século XIX recriou a noção de património ao acrescentar à valia estética dos imóveis históricos um significado colectivo poderoso e mobilizador. Laicizados pelo liberalismo, os Mosteiros da Batalha e dos Jerónimos chegaram ao Estado Novo como lugares da pátria. Essa vinculação identitária estendeu-se a todas as artes. No Roteiro, as Tapeçarias de Pastrana não descrevem apenas os "feitos do Norte de África» - são o seu melhor testemunho. Os painéis de Nuno Gonçalves não figuram apenas os «homens que preparam a epopeia dos Descobrimentos" - são o seu retrato mais fiel. Não é portanto a novidade que caracteriza estas ideias, mas a durabilidade e o mimetismo em relação aos velhos discursos de Latino Coelho, Inácio de Vilhena Barbosa e Sousa Viterbo, que deram formulações lapidares ao culto patriótico dos monumentos. ${ }^{4}$

\footnotetext{
3 HERCULANO, Alexandre. «Os monumentos» e «Mais um brado a favor dos monumentos", publicados sem assinatura na revista O Panorama, Lisboa, volumes I, II e III, 1838 e 1839, e refundidos em 1872 e 1873 para integrar o volume II dos Opúsculos com o título de "Monumentos pátrios".

${ }^{4}$ Roteiro da Arte Portuguesa, p. 32; COELHO, J. M. Latino. Arte e Natureza. Lisboa: Empresa Literária Fluminense, s.d., pp. 71-74; BARBOSA, Inácio de Vilhena. Monumentos de Portugal. Históricos, artísticos e arqueológicos. Lisboa: Castro \& Irmão Editores, 1886, p. C, e prefácio a Possidónio da Silva, Resumo Elementar de Arqueologia
} 
Apesar da invocação patriótica, a doutrina exposta no Roteiro contém uma defesa dos museus e do património que é salutar e parece comum. O incremento das visitas de estudo, procurado pela Campanha Nacional de Educação de Adultos, continua a ser uma tarefa actual. Para cumprir esse objectivo, destaca a «importância histórica, social e cultural da Arte», dá indicações precisas sobre o modo de visitar museus e monumentos, apresenta-os por distritos e concelhos e proporciona um significativo «documentário fotográfico». Estes intuitos parecem simplesmente naturais. O que é diferente e merece a nossa atenção é o desejo de expor o sentido da arte portuguesa ou, melhor dizendo, o sentido português da arte.

\section{O sistema nacional}

A arte é reiteradamente associada à nação. Na primeira parte, este propósito tem uma formulação geral. Na segunda, concretiza-se numa análise histórica através da qual se observa o desenvolvimento artístico e o afloramento das especificidades colectivas.

O Roteiro da Arte Portuguesa pertence a uma época em que a identidade artística nacional constituía um sistema forte, estabilizado, parecendo quase inexpugnável. As culturas nacionais desenvolvidas desde o Romantismo sedimentaram a convicção de que a arte se particulariza de acordo com o meio, a psicologia dos povos e as tradições populares. No final do século XIX, era comum pensar que toda a arte tem uma pátria, isto é, apresenta particularidades relacionadas com as pessoas, a cultura e a paisagem. A crença adquiriu força, tornou-se um axioma e elevou a

Cristã, Lisboa, Lallemant Frères Imprensa, 1887, p. 7; VITERBO, Sousa Cem Artigos de Jornal. Lisboa: Tipografia Universal, 1912, p. 8. 
nação a principal fundamento da arte. É um facto certo e seguro do Roteiro, que assim ignora os violentos conflitos nascidos com a difusão da linguagem apátrida das vanguardas. A arte reflecte as características de cada povo. Constitui «o seu melhor retrato, físico e mental", "O seu melhor índice e guia». - Eis uma das principais conclusões. 5

O leitor é convidado a aceitar o seguinte axioma: "Cada povo tem a sua arte característica, bem definida, de acordo com as suas tendências e as suas características psicológicas. É por isso que podemos falar numa arte egípcia, numa arte grega, numa arte romana.» ${ }^{6}$ A diversidade dos povos apresenta-se como uma evidência. Já os motivos dessa diferença são mais difíceis de estabelecer.

\section{Diferenciação caracterológica}

Durante séculos, era corrente a presunção de que a natureza dos povos variava por causa do clima. O tópico estendeu-se à arte, onde, com a designação de meio, se tornou um lugar-comum no século XIX e, reestruturado sob o epíteto de regionalismo, desempenhou um papel decisivo nos debates arquitectónicos do século XX.

O Romantismo atribuiu aos povos uma diferenciação decorrente do génio. Esta palavra, apropriadamente vaga, foi sendo substituída pela caracterologia étnica, em crescendo a partir dos anos de 1870. A caracterologia étnica sempre existiu, e permanece hoje como uma atracção fatal dos discursos nacionais. No entanto, os antropólogos de finais de Oitocentos deram-lhe sofisticação científica. Associaram os povos a certos traços psicológicos e desencadearam narrativas identitárias baseadas nos cruzamentos étnicos. De Teófilo Braga a

\footnotetext{
5 Roteiro da Arte Portuguesa, p. 35.

${ }^{6}$ Idem, p. 30.
} 
Jorge Dias, a cultura portuguesa passou a fazer-se com estas metáforas unificadoras que atravessam os tempos, as ideologias e as áreas disciplinares.

Os atributos caracterológicos têm a vantagem ontológica de remeterem para a intemporalidade. São uma condição necessária a que o artista não se pode eximir. Estabelecem um padrão reconhecível dentro das variações históricas. Até final do século XIX, a história da arte em Portugal é um fenómeno acidentado, inorgânico, dependente de bruscas transformações históricas. Na transição para o século XX, porém, a caracterologia étnica sustentou uma explanação própria e poderosa. A história da arte não se fazia de acasos, como a mítica viagem de Van Eyck a Portugal no princípio do século XV. A arte exprimia uma personalidade colectiva, que se tornou o santo graal da historiografia nacionalista. Na sucessão de estilos, devia procurar-se a manifestação da autonomia espiritual da nação, a sua diferença e, aqui e ali, a sua superioridade. A diferença e a superioridade seguem a par. No Roteiro da Arte Portuguesa, o esplendor do azulejo seiscentista parece maior porque manifesta «um sentido decorativo e uma largueza de emprego, que em mais parte alguma se encontra».7

\section{A história da arte como renovação indefinida do espírito nacional}

O primado da caracterologia reduziu as possibilidades de transformação. A história da arte converteu-se na história de um espírito nacional renovando-se indefinidamente. A caracterologia deu sentido às mudanças, explicou as particularidades nacionais de cada estilo, esclareceu as permanências e a longa duração.

7 Idem, p. 110. 
O leitor do Roteiro sabe, porque isso é intuitivo, que "cada época imprime à sua arte características perfeitamente definidas». Mas também é levado a concluir que a arte concede "preciosas lições acerca do estado de espírito do povo que a criou» numa determinada circunstância histórica. ${ }^{8}$ Sendo assim, deve pedir-se à história da arte que faça a biografia da nação, delineando a sua personalidade e explicando-a em cada época e em cada estilo.

A possibilidade de exibir as mudanças históricas sem prejudicar a visão unificada do «espírito nacional» foi um dos objectivos maiores de Reynaldo dos Santos (1880-1970), médico que encetou em 1921 uma frutuosa carreira como estudioso da arte portuguesa. Numa primeira fase, o seu trabalho recebeu o patrocínio de José de Figueiredo (1871-1937) que em 1910 publicara O Pintor Nuno Gonçalves e dera origem a uma renovação da perspectiva identitária.

O Roteiro segue a norma criada por estes dois autores, que elevaram o românico a matriz do gosto português. A procura de um estilo nacional decorreu em torno do manuelino desde a sua "descoberta" em 1842 até ao declínio do gosto revivalista no início de Novecentos. Coube a José de Figueiredo lançar em 1901 a possibilidade de o gosto português ter nascido com o românico e permanecido secularmente ligado a ele, constituindo-se como uma maneira própria que influenciou os estilos subsequentes. Este entendimento, retomado e desenvolvido por Reynaldo dos Santos, converteu-se num traço estruturante da historiografia nacionalista. Mais do que um estilo, o românico evidenciava uma "essência" portuguesa, uma "constante de sentimento", uma personalidade que define o espírito da arte em Portugal. ${ }^{9}$

\section{Idem, p. 31.}

9 FIGUeIRedo, José de Portugal na Exposição de Paris. Lisboa: Empresa da História de Portugal Editora, 1901, p. 9; PINA, Luís de "As origens do românico em Portugal: sua evolução e significado nacional. (Conferência pelo Dr. Reynaldo dos Santos, na Sociedade Martins Sarmento, de Guimarães, na noite de 29 de Janeiro de 
O românico durou mais do que seria previsível, permaneceu como um modo autóctone de edificar e pesou nas estruturas góticas subsequentes. Se as linhas mestras, a solidez e a traça geral de muitos edifícios góticos são "inspirados no românico", então pode concluir-se que só este "criou raízes profundamente nacionais».10 Existe uma relação directa entre as pequenas igrejas do Norte e o povo que nele habita e que, lê-se no Roteiro, ainda há sessenta anos sabia aparelhar o granito para as suas casas.

Embora o românico e o gótico ocorram como uma dicotomia estilística e caracterológica, a sua aglutinação naquilo que a historiografia no Estado Novo chamou românico-gótico não traduz uma indecisão, um anacronismo ou um atraso português. Cinco décadas depois do livro de José de Figueiredo sobre a presença portuguesa na Exposição Universal de Paris e duas após a conferência em que Reynaldo dos Santos afirmou que Portugal "sempre falou românico", a tese oficializada pelo Estado Novo era que a durabilidade do românico "representa uma resistência do nosso temperamento à introdução do estilo gótico». ${ }^{11} \mathrm{O}$ românico seria simples, rude e continha, acrescentamos nós, a ruralidade que era, desde o século XIX, um dos traços mais reconhecidos da identidade portuguesa.

Em suma, o Roteiro afirma que o "sentido nacional» existe no românico mas não no gótico, excepto em relação à escultura, sobretudo a tumular, onde o lirismo marcaria os movimentos calmos, as atitudes graves e o realismo sóbrio. Neste ponto, cita Reynaldo

1927)", Ilustração Moderna, Porto, ano II, n. ${ }^{\circ} 11$, Março de 1927, p. 262; Reynaldo dos Santos, "A arte medieval. Arquitectura, iluminura, artes menores", in: SAMPAIO, Albino Forjaz de (dir.), História da Literatura Portuguesa Ilustrada. Vol. I. Paris e Lisboa: Livrarias Aillaud \& Bertrand, s. d., pp. 72-77; SANTOS, Reynaldo dos. A Arquitectura em Portugal. Lisboa: Imprensa Nacional, 1929, p. 12; SANTOS, Reynaldo dos. Conferências de Arte. 2. ${ }^{a}$ série. Lisboa: Livraria Sá da Costa, 1943, pp. 21 e 26-27; SANTOS, Reynaldo dos. "Carácter da arte portuguesa através dos tempos", Colóquio. Revista de artes e letras. Lisboa: . $^{\circ} 14$, Julho de 1961, pp. 15-21 e 64.)

10 Roteiro da Arte Portuguesa, p. 85.

11 Idem, p. 86. 
dos Santos e eleva-o a autoridade. A personalidade artística portuguesa, definida no românico e tomando uma feição excepcional no manuelino e barroco, recusou o neoclassicismo e, ao chegar ao século XIX, confrontou-se com o revivalismo, que o Roteiro considera imitativo, fantasioso e falso.

\section{Uma ideia de Portugal}

O Roteiro da Arte Portuguesa consagra a interpretação caracterológica da identidade nacional e, nessa medida, aproveita a arte para veicular um conceito de Portugal. A lição desenvolvida por José de Figueiredo e Reynaldo dos Santos desagua numa gravidade absoluta, alheia ao tempo ou trazendo dele apenas o que parece definitivo.

"A arte da época dos Descobrimentos", patente no estilo manuelino e na escola portuguesa de pintura, não representa apenas um período histórico. Ela exprimiria o acordo perfeito de uma entidade colectiva madura, dotada de personalidade própria. O essencialismo artístico aplicado aos Descobrimentos contém a virtualidade inultrapassável de enaltecer a unidade da nação, a ausência de alternativas individuais, a diferença portuguesa perante Espanha e o resto da Europa e até a relutância em relação ao estrangeiro, manifestada na escassa implantação do renascimento italiano.

\section{Indivíduo e liberdade}

O gosto artístico talvez seja uma das ausências mais inesperadas. O Roteiro espera desenvolver a sensibilidade dos leitores, mas não explicita uma opção dentro das correntes artísticas contemporâneas. Fica tão atrás no tempo que nem menciona o consagradíssimo naturalismo. Vale a pena pensar nos motivos desta singularidade. 
Não há espaço para o reconhecimento da individualidade do gosto porque todo o esforço está votado a provar a existência de uma personalidade artística portuguesa. O século XIX criou a identidade artística nacional, mas demorou a perceber que ela punha em causa um dos pilares do seu sistema estético: a originalidade individual. Pode um artista contradizer a nação em nome da sua liberdade? Esta pergunta dificilmente teria uma resposta positiva no século XIX. Em 1876, João Loesevitz, director da Revista Crítica de Belas-Artes (e de quem desconhecemos quaisquer outros elementos biográficos), publicou um curto artigo intitulado "Arte e Estado". A sua tese apresenta uma clareza meridiana. No contexto do liberalismo, o Estado deve difundir a arte sem ousar definir uma estética. A acção do Estado não pode ofender a liberdade do artista. ${ }^{12}$ A potencial oposição entre nação e indivíduo não era evidente. A liberdade individual constituía um valor fundamental desde que não afectasse os outros pilares do juízo estético: o belo ideal e o respeito pela natureza.

Este sistema foi posto em causa pelas vanguardas através daquilo que parecia uma originalidade desenfreada e pervertida. No pico do nacionalismo artístico, nos anos de 1930 e 1940, a liberdade individual ergueu-se como um excesso que deveria ser condicionado. Os limites decorreriam precisamente daquilo que a opinião dominante considerava serem os valores nacionais.

No Roteiro da Arte Portuguesa não há espaço para a dúvida nem para o debate. O leitor é levado a reconhecer que os «sentimentos mais altos e mais verdadeiros" dos artistas traduzem "os anseios e as certezas dos homens do seu tempo».13 O Roteiro não diz se o artista deve submeter-se ao "seu tempo" porque toma por adquirida

12 LOESEVITZ, João. "Arte e Estado", Revista Crítica das Belas-Artes. Lisboa: n. ${ }^{\circ} 2$, 1 de Dezembro de 1876, pp. 33-36.

13 Roteiro da Arte Portuguesa, p. 33. 
a obediência entusiástica aos valores da intemporalidade nacional. $O$ artista transporta uma responsabilidade que transcende a estrita individualidade. Consciente da sua nacionalidade, deve contribuir para modelar o "carácter» e conservar as «virtudes» do povo a que pertence. ${ }^{14}$ Não é de liberdade que se trata, mas de responsabilidade. E no Estado Novo a responsabilidade está acima da liberdade individual. Nos anos cinquenta, no que a este assunto diz respeito, vive-se uma "serenidade hiperbólica". A crença no sistema nacional das artes oficializou-se. É isso que se observa no manual para a educação de adultos. Em contrapartida, a realidade mostra as novas correntes artísticas a abandonar aceleradamente esse padrão identitário. O Roteiro é a peça historiográfica de uma época que teve os seus expoentes em José de Figueiredo e Reynaldo dos Santos. A sua firmeza estética e nacional é, porém, uma ilusão quase anacrónica.

\section{A última conferência de Reynaldo dos Santos}

O Roteiro defende um sentido artístico português, mas esse sentido está cada vez mais em causa entre os artistas e os próprios historiadores de arte. Depois dos violentos conflitos identitários travados nos anos trinta, a historiografia artística emergiu como um lugar sereno, de certezas milenares. É uma serenidade ilusória que não é partilhada pelas novas gerações. Nos anos trinta e quarenta, as opiniões assumem facilmente um modo intransigente porque está em causa a prática artística imediata. Os artistas não se podem furtar a um debate que os implica, quer sigam a norma nacional quer optem pelo modernismo. Quando os patriotas julgaram estar vencendo o combate, estavam a perdê-lo entre os artistas mais jo-

14 Idem, p. 36. 
vens. A serenidade era historiográfica, dizia respeito ao passado (por vezes longínquo) e não à prática artística coeva cujos estereótipos identitários se revelavam pouco mobilizadores.

O Roteiro proporciona segurança ontológica através da apresentação de uma sensibilidade portuguesa intemporal, mas não reflecte as inquietações artísticas e foge a elas, interrompendo a análise no século XIX. A exposição histórica, serena, inteligível e isenta de dúvidas, está em grande medida desajustada da realidade. A última conferência de Reynaldo dos Santos, comentada por Marcello Caetano, ilustra o que pretendemos dizer.

O episódio marca o fim de uma época de grandes convicções. Em 1960 o nacionalismo cultural já ia perdendo relevância. Mas Reynaldo dos Santos, que emergira vinte anos antes como grande referência historiográfica, continuava a ser visto como um humanista loquaz, rápido no raciocínio e vivo nas réplicas. $\mathrm{O}$ apreço pela sua obra resultou em grande medida do carácter estruturante do ideário nacional, das vastas e compreensivas sínteses históricas orientadas pela caracterologia étnica e, por certo, dos recursos literários. Marcello Caetano fixou com nitidez a sua última conferência sobre história da arte, "aí por 1961", na Fundação Calouste Gulbenkian. «Foi extraordinária! Posso afirmar, mesmo, ter sido das mais notáveis e brilhantes conferências que escutei, pela eloquência da palavra e pela riqueza das concepções. Mas na sala havia duas dúzias de pessoas... Reynaldo compreendeu que tinha passado a sua época. E não tornou a falar em público.»15

15 CAETANO, Marcello. Minhas Memórias de Salazar. Lisboa, Editorial Verbo, 1977, p. 141 . 


\section{Conclusão}

O Roteiro da Arte Portuguesa apresenta um sistema estético e identitário desenvolvido por José de Figueiredo e Reynaldo dos Santos. Parte do princípio de que há uma sensibilidade portuguesa intemporal. Os valores artísticos exprimem um espírito nacional. Os monumentos não são apenas vestígios do passado, testemunhos de feitos grandiosos, mas também signos da renovação do espírito e do gosto da colectividade. As consequências destas concepções estendem-se ao plano da acção política.

Até ao final do século XIX, a história da arte não precisava de um móbil extra-artístico. Apesar da perenidade dos critérios de valorização estética, ela surgia como um percurso acidentado, inorgânico e sujeito a bruscas transformações devido ao jogo de influências entre artistas e países. Nesta conformidade, o Estado liberal sentia-se obrigado a apoiar a arte sem se imiscuir na estética.

Em Reynaldo dos Santos, no Roteiro da Arte Portuguesa e portanto na historiografia oficiosa do Estado Novo, a história da arte tem um sentido nacional, integra uma narrativa grandiosa e atemporal. A matriz românica, austera, naturalista ou lírica do gosto português estabelecia um vínculo que obrigava todos os artistas, todos os portugueses e o próprio Estado que, munido dessa convicção, podia e devia determinar a estética. A propaganda supõe certezas. A propaganda artística supõe certezas artísticas: uma estética, uma legitimidade e um sentido histórico. O Roteiro oferece-as. 